\title{
La oposición de los verbos ser y estar con adjetivos y participios desde la perspectiva comparativa español-polaco
}

\section{Resumen:}

La oposición de los verbos ser y estar, como ausente en polaco, es uno de los temas más recurrentes de la enseñanza del español como lengua extranjera en nuestro país y uno de los contrastes más evidentes entre ambos idiomas. En este artículo se analiza la posible analogía entre los significados de los dos verbos en sus usos copulativos y la información aportada por la categoría de aspecto gramatical polaco. Usando el método confrontativo (el análisis de las descripciones gramaticales existentes) y, ante todo, el comparativo de aproximación traductológica (el cotejo de los originales y sus traducciones) se intenta descubrir las regularidades que rigen la transferencia al polaco del contraste ser/estar en combinación con adjetivos y participios.

Palabras clave: oposición ser/estar, verbos copulativos, aspecto perfectivo/ imperfectivo, adjetivo, atributo

\begin{abstract}
:
The Opposition between the Verbs ser and estar with Adjectives and Participles from the Spanish-Polish Comparative Perspective

The opposition between the verbs ser and estar, being absent in Polish, is one of the most recurrent subjects of teaching Spanish as a foreign language in Poland and one of the most evident differences between both languages. This article analyzes the possible analogy between the meanings of the two verbs in their
\end{abstract}


copulative uses and the information provided by the Polish category of grammatical aspect. By the usage of the confrontational method (the analysis of the existing grammatical descriptions) and, first of all, the comparative method with a translation approach (the comparison of the originals and their translations), the paper attempts to discover the regularities that rule the transfer of the ser/estar opposition in combination with adjectives and participles to Polish.

Keywords: ser/ estar opposition, copulative verbs, perfective/ imperfective aspect, adjective, predicative

La oposición de los verbos ser y estar es uno de los temas más arduos y trabajados de la enseñanza del español como lengua extranjera. Su dominio plantea dificultades, no solo para estudiantes principiantes, sino, según Gutiérrez Aráus (1991: 315), también en los niveles más altos. Ocurre así porque numerosos idiomas (entre ellos el polaco) carecen de un fenómeno lingüístico análogo. En este trabajo, partiendo del método confrontativo, es decir, del análisis de las descripciones de ambos verbos en polaco y en español, nos gustaría llamar la atención sobre una posible equivalencia entre ciertos usos copulativos de ser y estar y el aspecto gramatical polaco. A continuación, intentaremos comprobar esta hipótesis por medio del análisis comparativo de aproximación traductológica (el cotejo de los originales y sus traducciones) ${ }^{1}$.

La diferencia semántica entre los verbos en cuestión se describe tradicionalmente a través de la oposición entre "cualidad, expresada por ser, y estado, expresado por estar” (Gutiérrez Aráus, 1991: 318-319). Gómez Torrego (2002) añade que para explicar el contraste ser/ estar se usa también la pareja de antónimos permanente/ momentáneo y afirma que se reserva el verbo ser para las descripciones

1 El análisis comparativo de aproximación traductológica es una propuesta de traducir el término badania przekładowe de Kozłowska (1985) inventado para distinguir este método de otros dos utilizados en la gramática contrastiva: el análisis comparativo (comparación de las descripciones de un fenómeno lingüístico en ambas lenguas) y el análisis contrastivo (comparación de un fenómeno en los textos originales en ambas lenguas). El término español se ha utilizado ya en otras ocasiones, p. ej. en Głowicka (2014: 183-184). 
y clasificaciones, mientras que estar suele expresar "producto de un cambio, real o pensado" (ibidem: 63). Como equivalente de ambos verbos españoles, los diccionarios bilingües español-polaco proponen en primer lugar el verbo być, claramente incapaz de transmitir por sí mismo esas diferencias. En consecuencia, las entradas ser y estar de dichos diccionarios son normalmente muy largas porque por medio de varias notas intentan determinar los contextos en los cuales być puede o no puede sustituir cada uno de ambos verbos, por ejemplo, en la entrada de ser: "estado permanente, cualidad constante [...] profesión, cargo, nacionalidad [...] genio" (Wawrzkowicz y Hiszpański, 1983: 674-675), en la entrada de estar: "estado pasajero" (ibidem: 357).

Partimos del hecho de que ser y estar funcionan, además de como auxiliares en las perífrasis ser + participio y estar + gerundio, sobre todo de dos maneras: como verbos predicativos y copulativos. Son predicativos cuando aparecen con su significado pleno y constituyen los verdaderos núcleos del predicado (ser, con el significado de 'existir, celebrarse, tener lugar' y estar, como sinónimo de permanecer, hallarse (Hernández, 2006: 106), encontrarse). En ese estudio nos van a interesar principalmente los usos copulativos, es decir, los contextos donde ser y estar sirven para unir sujetos con atributos, en los que su carga semántica disminuye y "tienen un signo léxico de alusión tan extensa que requieren la precisión de un término adyacente para poder hacer una referencia concreta" (Alarcos Llorach, 1994: 258).

Los atributos sobre los que se desplaza el núcleo semántico del predicado nominal pueden ser representados por diferentes clases de palabras y formas gramaticales; no obstante, la oposición ser/estar se manifiesta en realidad solo en los casos en que se unen con ambos verbos. Por combinarse solo con ser, quedan excluidos entonces los pronombres, sintagmas nominales, infinitivos y sustantivos (en este sentido son una excepción los modismos de tipo estar pez/ moscal fenómeno) y, por ser compatibles únicamente con estar, los pocos gerundios aceptables en la función de atributo. Dejando para otra ocasión el análisis de atributos en forma de adverbios de modo, oraciones subordinadas y sintagmas preposicionales, vamos a dedicarnos aquí a los adjetivos y a los participios (o sintagmas adjetivales). 
Mientras que es evidente la posible unión de ambos copulativos con los adjetivos y de estar con los participios, estos últimos se combinan con ser solo cuando funcionan como adjetivos y en la voz pasiva perifrástica. Además, por lo general, los españoles, como afirma Perlin (1993), evitan la construcción ser + participio, sustituyéndola con frecuencia por la pasiva refleja u oraciones impersonales con se (ibidem: 124). Las búsquedas en el Corpus de Referencia del Español Actual (CREA) lo confirman: por ejemplo, a 70 casos de la expresión están escritos les corresponden solo 8 concordancias de son escritos y a 94 casos de está cerrada, únicamente 4 se corresponden con es cerrada, etc. ${ }^{2}$ A pesar de todo, la construcción ser + participio puede ser vista también como equivalente al predicado nominal. Por ejemplo, Alarcos Llorach (1994: 141) afirma que "Si en El campeón fue vencido se dice que hay un contenido pasivo y en El campeón fue vencedor no, se debe exclusivamente a la significación de la unidad vencido, y en ningún modo a la forma verbal [...]”.

Tanto para refutar como comprobar la manifestación del contenido pasivo en la estructura ser+participio se han esgrimido varios argumentos (véase, p. ej.: Gómez Torrego, 2002: 198-199); si bien no pretendemos resolver el problema en este lugar, nos interesa el comentario de Alarcos porque permite ver la construcción ser + participio como análoga a ser + adjetivo, estar + adjetivo y estar + participio, lo que a continuación nos posibilitará observar cierta regularidad.

Perlin (1993), comentando la unión de ser y estar con los participios, presenta las siguientes equivalencias en español-polaco:

El almacén es cerrado por el propietario a las siete. - Magazyn jest zamykany przez właściciela o siódmej.

El almacén está cerrado. - Sklep [sic!] jest (zostal) zamknięty (ibidem: 117).

2 Las búsquedas se realizaron con el filtro "España" para obtener exclusivamente los datos sobre la variedad castellano peninsular, donde la construcción ser + participio es menos frecuente (según, p. ej. Perlin, 1993: 124). 
Lo que llama la atención en este ejemplo es el hecho de que a verbos diferentes (ser y estar) y un atributo igual (cerrado) de la versión española les corresponden en la polaca un verbo igual (jest) y participios adjetivales pasivos (imiestowy przymiotnikowe bierne) en aspectos gramaticales opuestos (a ser, la forma imperfectiva [zamykany] y a estar, la perfectiva [zamknięty]). Como observó Nowikow (2017), la manera de entender la categoría de aspecto en español y en polaco es distinta a pesar de manejar los términos a primera vista simétricos: perfectivo-imperfectivo/ dokonany-niedokonany. Mientras que lo perfectivo en español presupone una acción terminada en un tiempo limitado X, en polaco está relacionado con la conclusión procesal, es decir, con un resultado de la acción (ibidem: 159). En la gramática española se comenta el valor resultativo de estar (Conti Jiménez, 2004: 21-44); sin embargo, no se ha asociado hasta ahora con la cuestión del aspecto en la gramática contrastiva español-polaco.

A partir del ejemplo presentado, puede afirmarse que, por lo menos en algunos contextos, la oposición ser/estar podría servir para expresar en español los mismos contenidos que se transmiten en polaco por medio de las formas de aspecto imperfectivo (-resultado de la acción) y de aspecto perfectivo (+resultado de la acción). Así que la oposición ser/estar se podría sumar a los recursos disponibles en español que también se emplean para referirse a la falta o la presencia de un resultado. Tales recursos los enumera Nowikow (2017: 164-165), comentando ejemplos:

Leí el libro.

Przeczytatem książkę.

Me comíl la sopa.

Zjadtem zupę.

Según el autor, el español puede transmitir los mismos contenidos que el aspecto polaco (la oposición -resultado/ +resultado) a través del tiempo pretérito combinado con: 
- la determinación de tipo anafórico aportada por el articulo (el, la),

- el carácter discontinuo (contable) del sustantivo en función de complemento (el libro) o

- el énfasis semántico-estilístico de la relación entre la acción y el agente de esta marcado mediante el pronombre con función de dativo ético (me) (Nowikow, 2017: 165).

De lo anterior se deriva que los verbos ser y estar también son capaces de transmitir la información análoga al aspecto verbal polaco ([-resultado] / [+resultado]), por lo menos en unión con los participios. Hay que observar que, para hacerlo, ser y estar tienen que aparecer en los tiempos imperfectivos (es decir, los simples excepto el indefinido). En los demás casos la oposición - desde el punto de vista contrastivo- se neutraliza y ambos equivalen al aspecto perfectivo polaco:

$$
\begin{array}{ll}
\text { es cerrado - jest zamykany } & \text { está cerrado - jest zamknięty } \\
\text { [-resultado] } & \text { [+resultado] } \\
\text { era cerrado - był zamykany } & \text { estaba cerrado - był zamknięty } \\
\text { [-resultado] } & \text { [+resultado] } \\
\text { fue cerrado - został zamknięty } & \text { estuvo cerrado - został zam- } \\
\text { [+resultado] } & \text { knięty (i pozostał zamknięty } \\
& \text { przez pewien czas) [+resultado] }
\end{array}
$$

Naturalmente, surge el interrogante de si este rasgo de la oposición ser/estar se refleja en los textos traducidos. La lectura de las versiones polacas de algunas novelas españolas contemporáneas ${ }^{3}$ aporta ejemplos que parecen confirmar la capacidad de ser y estar para transmitir los contenidos propios del aspecto polaco, también cuando acompañan a los adjetivos.

Antes de presentar las citas concretas, es preciso notar que, para evitar dudas de si es realmente la oposición ser/estar la que porta la información [-resultado] / [+resultado], hay que fijarse en si los adjetivos cumplen dos requisitos. Primero, si son compatibles con ambos verbos: se excluyen entonces, p. ej. palabras como: lógico, posible, importante (como atributos solo de ser) olleno, vacío, contento,

3 Véase: bibliografía. 
satisfecho (como atributos exclusivos de estar). En segundo lugar, si son adjetivos que no cambian de significado según se combinen con ser o estar (como: despierto, listo, negro, vivo, interesado, ...), entonces, la oposición ser/estar es neutralizada:

(1) SER: ¿ No le parece extraño que, siendo una mujer tan interesada [...] olvide de pronto su indignación para ponerse a hablar tranquilamente de ajedrez?... (T 62)

Czy to nie dziwne, że kobieta tak interesowna [...] nagle zapomina o oburzeniu i spokojnie gawędzi o szachach...? (306)

ESTAR: — ¿Cómo que es posible? —el anticuario estaba confuso e interesado a un tiempo-. (T 27)

- Jak to "możliwe"? - Antykwariusz stanąl jednocześnie zdumiony i zaintrygowany. (136)

(2) SER: - [...] Miquel Moliner es una pista muerta.

-O esa Nuria es muy viva. (S 294)

- [...] Miquel Moliner to fałszywy trop.

- Albo ta Nuria jest tak szczwana, że wyprowadza nas w pole. (267)

ESTAR: $-[\ldots]$ ¿No estás vivo? Pues no te quejes, hombre. (A 18)

- [...] Żyjesz? To się nie skarż, człowieku. (37)

La lista de los adjetivos que pueden acompañar cada verbo es larga y abierta. Como ya hemos dicho, el equivalente acuñado (es decir, en términos de Hurtado Albir (2007: 250), la palabra consagrada como tal por los diccionarios o por el uso) de ambas cópulas en polaco es el verbo być que desde la perspectiva española resulta vago:

ser tranquilo / estar tranquilo = być spokojnym ser soltero / estar soltero $=$ być kawalerem

4 Las letras indican la fuente de la cita y se corresponden con las letras en la bibliografía (véanse: fuentes primarias), pospuestas a la información bibliográfica sobre el original. Las traducciones van acompañadas solo del número de página. 
Esta técnica de traducción es frecuente y aceptable porque el contexto normalmente precisa si se trata de una cualidad permanente o un estado momentáneo:

(3) SER: Para lo que yo quiero hablarle a usted, nada importa que sea casada o soltera. (C 35)

A jeśli chodzi o to, o czym chcę z panią pomówić, to nie ma żadnego znaczenia, czy będzie pani zamężna czy wolna. (202)

ESTAR: Mi hija estaba por entonces soltera [...] (S 87)

Moja córka wówczas była panną [...] (78)

Pero se dan también las situaciones cuando se aplica un trato diferente a cada uno de los verbos. Como un sustituto de ser, en la mayoría de los casos los traductores eligen być que en polaco es uno de los pocos imperfectiva tantum, mientras que en caso de estar se observa, entre otras, la técnica de compresión:

(4) Estás pálido. (S 369)

Zbladleś. (332)

(5) - Si alguien me hubiese dicho que iba a seguir la pista de un posible asesino sobre un tablero de ajedrez, le habría dicho que estaba loco. (T 58).

- Gdyby ktoś mi powiedział, że będę iść śladem mordercy po szachownicy, uznałabym, że oszalal. (284)

(6) Estás loco, Julián, pero eso no es novedad. (S 329)

Całkiem zwariowałeś, no ale wiemy o tym nie od dzisiaj. (297)

(7) [...] desde que se fugó con el astorgano, estaba muy guapa y alegre [...] (M 16)

[...] od czasu jak uciekła z tym facetem z Astorgi, poweselała i wyladniała $[\ldots]$ (75)

(8) Dos castañas estaban frías [...] (C 14)

Dwa kasztany wystygły. (77)

Como se ve, en las citas aparecen predicados compuestos de la cópula estar y los atributos: pálido, loco, guapo, alegre, frío y en estos contextos denotan el resultado de un cambio. En polaco se expresan 
a través de una sola unidad: un verbo en el aspecto perfectivo que se manifiesta claramente por medio de los prefijos $z-$, o- y po-, wy- unidos a las raíces verbales correspondientes a las raíces de adjetivos originales (pálid-=blad-, loc- =szalon-, wari-, guap-=ładn-, alegr-=wesel-). Además, todos los verbos polacos aparecen en el tiempo pretérito a pesar del presente original en los ejemplos 4 y 6 , lo cual indica que en la lengua meta se presenta el final del proceso (p.ej., zwariowateś - 'te has vuelto loco') frente al resultado presentado como estado actual en la versión española (estás loco).

Parece que este procedimiento de expresar el contenido resultativo de estar podría funcionar de manera bastante regular en el caso de otros adjetivos: estar triste - posmutnieć, estar calvo - wytysieć, estar alto - wyrosnać, estar inquieto - zaniepokoić się, estar tonto zgłupieć, estar tranquilo - uspokoić się. Ninguno de los verbos polacos podría sustituir los mismos adjetivos utilizados con el verbo ser, ya que todos expresan resultado, efecto de un cambio y no se aplican en las descripciones.

Algunos usos de estar con los participios incompatibles con ser, en ejemplos muy parecidos a los anteriormente expuestos, teóricamente también podrían confirmar la capacidad de estar de expresar el contenido aportado en la lengua polaca por el aspecto perfectivo [+resultado]:

(9) Julián Carax estaba muerto. (S 497)

Julián Carax umarł. (449)

(10) — Te aseguro que de Álvaro estoy curada. (T 4)

- Możesz być pewna, że wyleczyłam sięz Alvara. (21)

A primera vista, estamos ante una situación análoga a la de los verbos anteriores, ya que en la traducción también se observa un atributo amalgamado con la cópula en una sola unidad; los verbos polacos aparecen en el tiempo pretérito y el aspecto perfectivo [+resultado], el verbo wyleczyć contiene el prefijo perfectivo wy- y el verbo umrzeć se opone a la forma imperfectiva umierać. Sin embargo, por falta de parejas análogas con ser no somos capaces de comprobar si la perfectividad se debe a la presencia del verbo estar o al contenido léxico del 
atributo. Bosque en su artículo "Sobre el aspecto en los adjetivos y en los participios" distingue un grupo de los adjetivos perfectivos que "denotan una acción que desemboca en un resultado" (1990: 184), y propone la prueba siguiente para identificarlos: son los que pueden ser modificados por adverbios de aspecto, como enteramente, completamente, o por el giro del todo. Gutiérrez Aráus añade que también se combinan con una vez y ya (1991: 321).

El Corpus de Referencia del Español Actual, que usamos para comprobar las posibilidades combinatorias de los atributos, confirma el carácter perfectivo de palabras como muerto y curado ${ }^{5}$ (entre paréntesis aparece el número de resultados encontrados): completamente muerto (4), enteramente muerto (1), muerto del todo (15), una vez muerto (38), ya muerto (137); completamente curado (8), enteramente curado (0), curado del todo (5), una vez curado (3), ya curado (12). Para confirmar el carácter perfectivo de las palabras a las que se aplica el test basta ya una aparición de cada secuencia. La falta de concordancias de enteramente curado parece casual frente al hecho de que curado resulta compatible con los demás adverbios y giros. Así que en el caso de muerto, curado y atributos análogos la perfectividad no tiene que ver con la oposición ser/estar (porque contamos con solo uno de los miembros de esta oposición).

De todos modos, hay que reconocer que la oposición ser/estar no garantiza la transmisión de la información [-resultado]/[+resultado] en todos los contextos. El uso del verbo perfectivo a veces es gramaticalmente correcto, pero la expresión de la conclusión procesal no parece bien justificada por no saber si ha tenido lugar un proceso, o solo se habla de un estado:

(11) Toqué las bombillas y comprobé que estaban frías, cosa, por lo demás, poco reveladora puesto que aún entraban por la ventana los últimos rayos del sol. (A 37)

5 Las búsquedas se han realizado solo para la versión masculina singular de muerto y curado, ya que el género y el número no influyen en su combinatoria. 
Dotknąłem żarówek i stwierdziłem, że są zimne, co zresztą niewiele nam powiedziało, zważywszy, że przez otwarte okno wpadały ostatnie promienie słońca. (77)

$=$ stwierdziłem, że wystygły?

(12) Lo [el cuadro-JW] habían llevado unas horas antes y estabas alegre como una chiquilla. (T 73)

Przywieźli go parę godzin wcześniej, cieszyłaś się jak mała dziewczynka. (359)

= poweselałaś/ucieszyłaś się jak mała dziewczynka?

La compresión resulta imposible si el sujeto de estar no admite el proceso, cuyo resultado podría manifestarse a través del atributo:

(13) Montegrifo se volvió hacia Julia con aire reflexivo. Sus ojos estaban fríos como el hielo. (T 11)

Montegrifo zwrócił się zamyślony ku Julii i spojrzał na nią lodowatym wzrokiem. (55)

*Jego oczy wystygły jak lód.

Además de usos figurados (como el de arriba), la compresión la excluyen también los valores habitual y actual del tiempo gramatical utilizado. En estos casos en el centro parece estar el proceso en su desarrollo o el estado mismo:

(14) Loliña Moscoso es guapa a lo bravo, cuando se cabrea está más guapa aún [...] (M 18)

Lolińa Moscoso jest zabójczo ładna, kiedy się złości, robi się jeszcze ładniejsza $[\ldots](88)$

(15) Julia pensó que habría estado francamente guapa veinte años antes. (T 3)

[...] Julii przyszło do głowy, że ze dwadzieścia lat temu Menchu musiala być naprawdę ładna. (18)

(16) [...] estás muy guapa, Moncha [...] (M 33)

[...] ślicznie wyglądasz, Moncha [...] (156)

En resumen, el idioma polaco carece de una oposición análoga a la de los verbos ser y estar; la lengua española, por su parte, no 
dispone del aspecto gramatical entendido como la información sobre la conclusión procesal. Como ser y estar en la pasiva perifrástica y la pasiva resultativa parecen portar el mismo contenido que el aspecto en polaco (-/+ resultado), nuestro objetivo ha sido observar si pueden realizar una función análoga también en sus usos copulativos con los adjetivos como atributos. Hemos aprovechado con este fin el análisis comparativo de aproximación traductológica. Los contextos revelados durante el análisis sugieren que la información sobre el resultado de la acción puede transmitirse a veces por medio de esta pareja de verbos, aunque no de manera regular. Parece que lo impiden los usos verbales de valor habitual y actual, como también la influencia del uso metafórico del atributo.

\section{Bibliografía}

\section{Fuentes primarias:}

Originales y traducciones

CELA, C. J. (1983), La colmena, HMB, Barcelona, [on-line] https://www. litmir.me/br/?b=125345, 20.10.2020 [C].

CELA, C. J. (1960), Ul, trad. Wojciechowska, K., Czytelnik, Warszawa.

CELA, C. J. (1985), Mazurca para dos muertos, Seix Barral, Barcelona, [online] https://www.litmir.me/br/?b=125329, 20.10.2020 [M].

CELA, C. J. (2007), Mazurek dla dwóch nieboszczyków, trad. Komarnicka, E., TMM Polska/Planeta Marketing: Axel Springer Polska, Warszawa. MENDOZA, E. (1982), El laberinto de las aceitunas, Seix Barral, Barcelona [A]. MENDOZA, E. (2013), Oliwkowy labirynt, trad. Chrobak, M., Znak, Kraków. PÉREZ-REVERTE, A. (2002), La tabla de Flandes, Alfaguara, Madrid, [online] https://www.litmir.me/br/?b=125167\&p=1, 20.10.2020 [T].

PÉREZ-REVERTE, A. (2009), Szachownica flamandzka, trad. Łobodziński, F., Muza, Warszawa.

RUIZ ZAFÓN, C. (2017), La sombra del viento, Planeta, Barcelona [S].

RUIZ ZAFÓN, C. (2007), Cień wiatru, trad. Fabjańska-Potapczuk, B., Marrodán Casas C., Muza, Warszawa. 


\section{Corpus:}

REAL ACADEMIA ESPAÑOLA, Banco de datos (CREA) en línea: Corpus de referencia del español actual, [on-line] http://www.rae.es, 30.12.2019.

\section{Fuentes secundarias:}

ALARCOS LLORACH, E. (1994), Gramática de la lengua española, Espasa Calpe, Madrid.

BOSQUE, I. (1990), "Sobre el aspecto en los adjetivos y en los participios”, en: Bosque, I. (ed.), Tiempo y aspecto en español, Cátedra, Madrid, pp. 177-210.

CONTI JIMÉNEZ, C. (2004), “Construcciones pasivas con estar”, ELUA, 18, pp. 21-44, https://doi.org/10.14198/ELUA2004.18.02.

GŁOWICKA, M. (2014), “Aproximación al estudio de las perífrasis incoativas españolas y sus equivalentes en polaco", en: Bułat Silva, Z., Głowicka, M., Wesoła, J. (eds.), Variación, contraste, circulación. Perspectivas lingüísticas en el hispanismo actual, Wydawnictwo Uniwersytetu Wrocławskiego, Wrocław, pp. 183-191.

GÓMEZ TORREGO, L. (2002), Gramática didáctica del español, Ediciones SM, Madrid.

GUTIÉRREZ ARÁUS, M. L. (1991), “Sobre ser/estar en español y su enseñanza a los anglohablantes”, ASELE, Actas III, pp. 315-326, [on-line] https://cvc.cervantes.es/ensenanza/biblioteca_ele/asele/pdf/03/03_0313. pdf, 30.12.2019.

HERNÁNDEZ, G. (2006), Análisis gramatical. Teoría y práctica, Sociedad General de Librería, Madrid.

KOZŁOWSKA, Z. (1985), „Badania przekładowe a badania konfrontatywne", en: Grucza, F. (ed.), Lingwistyka, glottodydaktyka. Materiały z VIII sympozjum zorganizowanego przez ILS UW, Jadwisin, listopad 1982, Wydawnictwo Uniwersytetu Warszawskiego, Warszawa, pp. 239-252.

NOWIKOW, W. (2017), “Tiempos verbales”, en: Nowikow, W. (ed.), Gramática contrastiva español-polaco, Wydawnictwo Uniwersytetu Lódzkiego, Łódź, pp. 127-178.

HURTADO ALBIR, A. (2007), Traducción y traductología. Introducción a la traductología, Cátedra, Madrid. 
PERLIN, O. (1993), Zarys gramatyki języka hiszpańskiego, Wydawnictwo Naukowe PWN, Warszawa.

WAWRZKOWICZ, S., HISZPAŃSKI, K. (1983), Podręczny słownik hiszpańsko-polski, Wiedza Powszechna, Warszawa. 